\title{
Astragaloside IV promotes the proliferation and migration of osteoblast-like cells through the hedgehog signaling pathway
}

\author{
LI-HUA GUO ${ }^{1,2}$, YU CAO $^{3}$, RUN-TAO ZHUANG $^{4}$, YAN HAN $^{2}$ and JUN LI ${ }^{1}$ \\ ${ }^{1}$ Department of Dental Implant Center, Beijing Stomatological Hospital, School of Stomatology, \\ Capital Medical University, Beijing 100050; ${ }^{2}$ Department of Stomatology, Xiyuan Hospital of China \\ Academy of Chinese Medical Sciences, Beijing 100091; ${ }^{3}$ Department of Integrated Emergency Dental Care, \\ Beijing Stomatological Hospital, School of Stomatology, Capital Medical University, Beijing 100050; \\ ${ }^{4}$ Department of Stomatology, Beijing Jiaotong University Community Health Center, Beijing 100044, P.R. China
}

Received February 8, 2018; Accepted August 30, 2018

DOI: $10.3892 / \mathrm{ijmm} .2018 .4013$

\begin{abstract}
The present study aimed to investigate the effects of astragaloside IV on osteoblast-like cell proliferation and migration, in addition to the underlying signaling pathway. In order to observe the effect on proliferation, a Cell Counting Kit- 8 assay and flow cytometry were used. To detect cell migration ability, cell scratch and Transwell cell migration assays were performed. The RNA and protein expression levels of hedgehog signaling molecules, including Sonic hedgehog (SHH) and GLI family zinc finger 1 (GLI1), were examined by reverse transcription-quantitative polymerase chain reaction and western blot analyses. To inhibit the hedgehog signaling pathway, cyclopamine was used. Astragaloside IV, at a dosage of $1 \times 10^{-2} \mu \mathrm{g} / \mathrm{ml}$ in MG-63 cells and $1 \times 10^{-3} \mu \mathrm{g} / \mathrm{ml}$ in U-2OS cells, resulted in the enhanced proliferation and migration of cells, and the gene expression levels of the $S H H$ and $G L I I$ were significantly increased. The combination of astragaloside IV and cyclopamine reduced MG- 63 and U-2OS cell proliferation and migration, and inhibited the gene expression of $S H H$ and GLII. Astragaloside IV enhanced the proliferation and migration of human osteoblast-like cells through activating the hedgehog signaling pathway. The results of the present study provide a rational for the mechanistic link in astragaloside IV promoting the proliferation and migration of osteoblasts via the hedgehog signaling pathway.
\end{abstract}

Correspondence to: Professor Jun Li, Department of Dental Implant Center, Beijing Stomatological Hospital, School of Stomatology, Capital Medical University, 4 Tiantan Xili, Dongcheng, Beijing 100050, P.R. China

E-mail: lijun3021@aliyun.com

Dr Yan Han, Department of Stomatology, Xiyuan Hospital of China Academy of Chinese Medical Sciences, 1 Xiyuan Caochang Road, Haidian, Beijing 100091, P.R. China

E-mail: hy1352111@163.com

Key words: astragaloside IV, osteoblast-like cell proliferation, osteoblast-like cell migration, hedgehog signaling pathway

\section{Introduction}

Dental implants have become the optimal treatment for dentition defects or missing teeth. Osseointegration is a key factor associated with implants and involves three stages: Peri-implant bone formation, reconstruction, and maturation. There are a series of events involved in the formation of bone, including proliferation, migration, and the recruitment of osteoblasts surrounding the implant surface. Previous studies have demonstrated that the migration, recruitment and adsorption efficiency of osteoblasts on the implant surface directly affects the occurrence, development and final effect of osseointegration (1). The process of osseointegration is affected by numerous factors in patients with systemic diseases, including diabetes, osteoporosis and cancer, and the success rates of implants in these patients are markedly reduced. A systematic review reported that, in the first year of loading, there is an increasing trend in the failure of dental implant teeth in patients with diabetes (2). Therefore, how to improve the osseointegration of implants in patients with certain diseases remains a focus of clinical investigations.

Various traditional Chinese medicine materials have been shown to promote osteoblast proliferation and migration and bone formation using in vivo and in vitro experiments (3). Astragali Radix is the root of Astragalus membranaceus (Fisch.) Bge.var. Mongholicus (Bge.) Hsiao or EE Astragalus membranaceus (Fisch.) Bge. Astragali Radix has been shown to exhibit a range of pharmacological effects, including anticancer, anti-inflammatory, antioxidant and anti-osteoporotic properties (4-10). Astragaloside IV (AST-IV, 3-O-b-D-xylopyr-anosyl-6-O-bD-glucopyranosylcyl-cloastragenol) is the principal effective compound isolated from Astragali Radix. A previous study reported that pretreatment with astragaloside IV significantly reverses the loss of neuronal cell viability and prevents $\mathrm{MPP}^{+}$-guided SH-SY5Y cell death, and that astragaloside IV has a neuroprotective effect (11). Astragaloside IV can enhance the proliferation of bone marrow mesenchymal stem cells in vitro, so as to the neural stem cells $(12,13)$ and promote angiogenesis and the reproduction of human umbilical vein endothelial cells (14). The combined application of 
astragaloside and tanshinone IIA promotes the migration of mesenchymal stem cells in cardiovascular disease therapy (15). Furthermore, a previous study revealed the effects of astragaloside IV on osteoclasts, demonstrating that astragaloside IV caused the inhibition of osteoclastogenesis and attenuation of osteolysis (16). However, the regulatory action of astragaloside IV on osteoblasts and the associated mechanisms remain, at present, to be fully elucidated.

A previous study demonstrated that the hedgehog signaling pathway regulates the differentiation of skeletal muscle cells in the process of skeletal repair and regeneration (17). In addition, the hedgehog signaling pathway is associated with bone formation, which can promote the proliferation and differentiation of chondrocytes and osteoblasts (18-21).

The hedgehog signaling pathway is conserved in evolution, and is key in embryonic development and homeostasis regulation, growth and cell migration in adult tissues (22). The hedgehog family contains three protein ligands, including sonic hedgehog (Shh), India hedgehog (Ihh) and desert hedgehog (Dhh). These signal via a mechanism involving two transmembrane proteins, namely smoothened (Smo) and patched (Ptc). When a hedgehog protein binds to Ptc, Smo is rendered constitutively active and activates an intracellular signaling cascade, leading to the upregulated transcription of the downstream nuclear transcription factor GLI family zinc finger (Gli)1 and Gli2 (23). Aberrant activation of the hedgehog signaling may lead to oncogenesis in various tissues, including basal cell carcinoma, medulloblastoma, pancreatic, colon and gastric cancer, and glioblastoma (24-28). However, the role of the hedgehog signaling pathway in the proliferation and migration of astragaloside IV in osteoblasts remains to be fully elucidated.

In the present study, human MG-63 and U-2OS osteoblast-like cells were treated with astragaloside IV, following which cell functions and the activation of hedgehog signaling were evaluated. Furthermore, the Smo inhibitor, cyclopamine, was used to inhibit the hedgehog signaling pathway, following which the gene expression levels of $\mathrm{SHH}$ and GLII and cell functions were evaluated.

\section{Materials and methods}

Reagents. Fetal bovine serum (FBS), modified Eagle's medium (MEM) and McCoy's 5A medium were obtained from HyClone Laboratories, GE Healthcare Life Sciences (Logan, UT, USA). Penicillin/streptomycin solution, phosphate-buffered saline (PBS), $0.05 \%$ Trypsin-EDTA and dimethyl sulfoxide (DMSO) were obtained from Invitrogen; Thermo Fisher Scientific, Inc. (Waltham, MA, USA). Astragaloside IV and cyclopamine (purity $>99 \%$, HPLC) were obtained from Sigma-Aldrich, Merck Millipore (Darmstadt, Germany). The chemical structure and molecular weight of astragaloside IV is shown in Fig. 1. The astragaloside was dissolved in DMSO, and the concentration of the original solution was $25 \mu \mathrm{g} / \mathrm{ml}$. The stock solution was diluted according to the treatment group when used; the DMSO did not exceed $0.5 \%(\mathrm{~V} / \mathrm{V})$.

Cell culture. The MG-63 and U-2OS human osteosarcoma cell lines were obtained from American Type Culture Collection (Manassas, VA, USA). The MG-63 and U-2OS cells were cultured in MEM and McCoy's 5A medium supplemented with $10 \%$ FBS, respectively. The two cell lines were incubated at $37^{\circ} \mathrm{C}$ in a $5 \% \mathrm{CO}_{2}$ humidified atmosphere.

Cell Counting Kit-8 (CCK-8) assay. Cell growth was evaluated using a CCK-8 assay (Dojindo Molecular Technologies, Inc., Shanghai, China). The cells were plated in 96-well plates, $100 \mu 1$ of medium was added to each well, which contained 10,000 cells. The cells were cultured overnight and were then treated with gradient dilutions of astragaloside IV $\left(1 \times 10^{-5}\right.$, $1 \times 10^{-4}, 1 \times 10^{-3}, 1 \times 10^{-2}, 1 \times 10^{-1}, 1$, and $10 \mu \mathrm{g} / \mathrm{ml}$ concentrations). After $48 \mathrm{~h}, 100 \mu \mathrm{l} \mathrm{CCK} 8$ reagents were mixed into each well. Following an additional incubation at $37^{\circ} \mathrm{C}$ for $4 \mathrm{~h}$, the absorbance value of each well at $450 \mathrm{~nm}$ was measured using a VERS Amax microplate reader. The number of living cells measured by the absorbance at the wavelength $450 \mathrm{~nm}$ was measured with a monochromator microplate. Cell viability $=[(\mathrm{As}-\mathrm{Ab})] /[(\mathrm{Ac}-\mathrm{Ab})] \mathrm{x} 100 \%$; where As is the absorbance of the astragaloside IV group, Ac is the absorbance of the control group, and $\mathrm{Ab}$ is the absorbance of blank group.

Flow cytometry. The cells were seeded in 6-well plates with $2 \mathrm{ml}$ of complete growth medium/well, containing the appropriate number of cells to yield $60 \%$ confluence $12 \mathrm{~h}$ following plating. After $12 \mathrm{~h}$, the complete growth medium was replaced with serum-free medium for $24 \mathrm{~h}$. After $24 \mathrm{~h}$, the cells were cultured in complete growth medium and treated with astragaloside IV or astragaloside IV combined with cyclopamine for $48 \mathrm{~h}$. BrdU $(1 \mathrm{mM} / \mathrm{ml})$ was then added for $4 \mathrm{~h}$ at $37^{\circ} \mathrm{C}$, and the cells were harvested. The cells were stained with anti-BrdU and 7-AAD using the BD Pharmingen ${ }^{\text {TM }}$ BrdU Flow kit (BD Biosciences, San Diego, CA, USA) according to the manufacturer's protocol. The cell cycle distribution was determined by flow cytometry (FACSAria ${ }^{\mathrm{TM}}$ II, BD Biosciences).

Wound-healing assay. Cell migration was measured using a wound-healing assay. The cells were seeded in 6-well plates and, when the cells had formed a confluent monolayer, a p200 micro-pipette tip was used to create a scratch in a straight line. Culture medium was used to clean the cells once and they were incubated in $0.1 \%$ FBS culture medium. Images of the cells at multiple points along the scratch were captured every $24 \mathrm{~h}$ using an inverted microscope. Images were captured at x100 magnification.

Transwell cell migration assay. The cells were harvested following treatment with astragaloside IV for $48 \mathrm{~h}$. The cells were then suspended in serum-free medium and placed in the upper chamber of the Transwell array $(8-\mu \mathrm{m}$ pore size; Merck Millipore). Medium containing 20\% FBS was added to the lower chamber, following incubation at $37^{\circ} \mathrm{C}$ for $48 \mathrm{~h}$, a cotton swab was used to carefully wipe away the cells in the upper chamber. The migrated cells that had adhered to the membrane of the lower chamber, were fixed in $4 \%$ formaldehyde solution for $10 \mathrm{~min}$, and stained with $0.1 \%$ crystal violet for $15 \mathrm{~min}$. The numbers of migrating cells were then counted with an inverted microscope. The values were averaged and images were captured.

RNA isolation and reverse transcription-quantitative polymerase chain reaction ( $R T-q P C R)$ analysis. The extraction of total cell RNA was performed using TRIzol reagent 

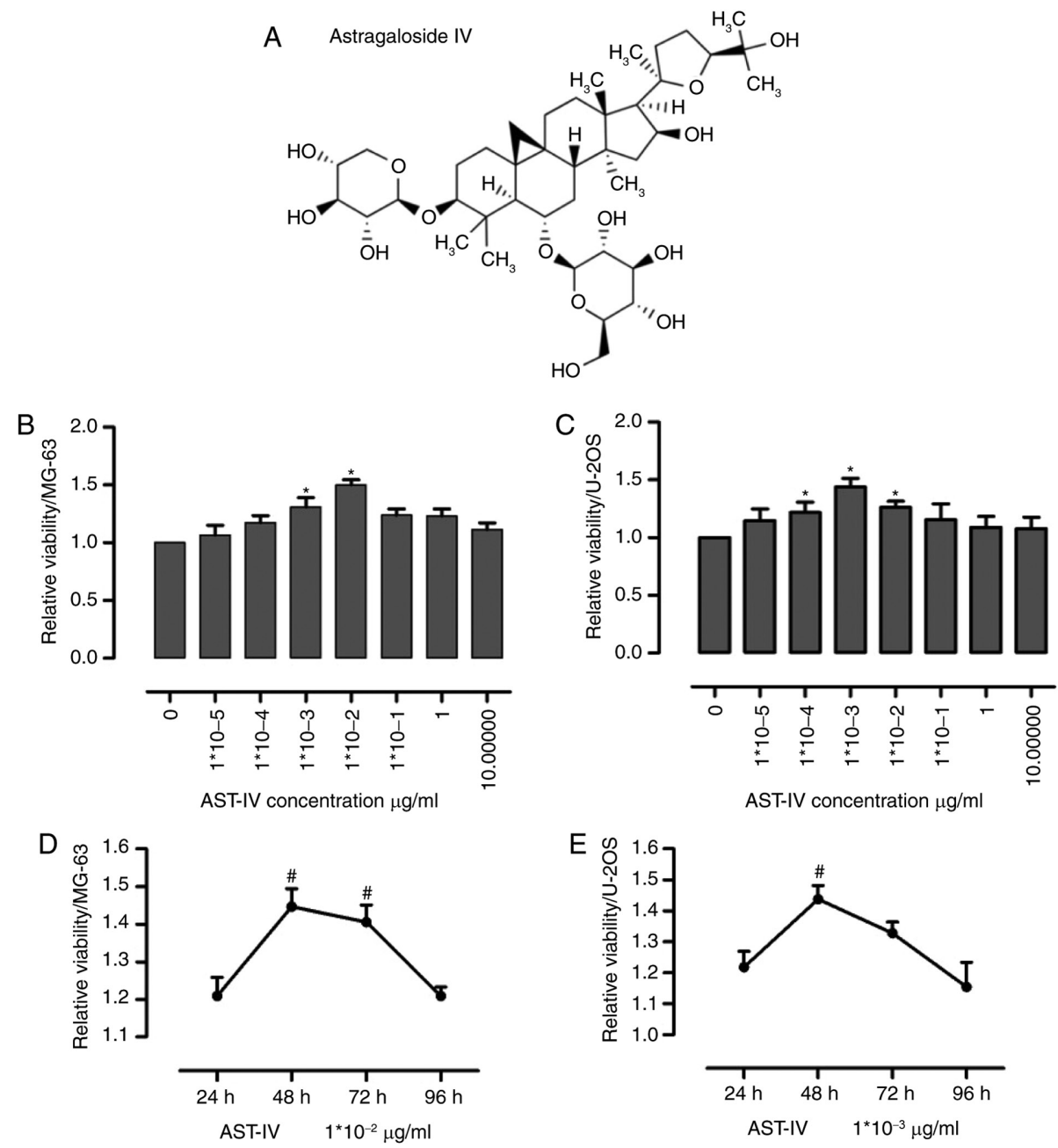

Figure 1. AST-IV enhances human osteoblast-like cell growth and proliferation. (A) Structure of AST-IV (structural formula, C41H68O14; molecular weight, 784.97). (B) MG-63 and (C) U-2OS cells were treated with DMSO as controls or various concentrations of AST-IV for 48 h. Cell viability was determined

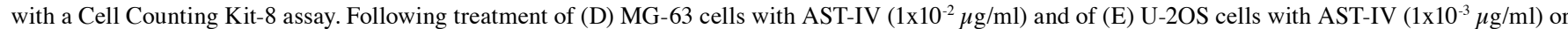
DMSO as a control for $24,48,72$ and $96 \mathrm{~h}$, cell viability was determined. ${ }^{*} \mathrm{P}<0.05$, AST-IV group compared with control group and ${ }^{\#} \mathrm{P}<0.05$, compared with the $24 \mathrm{~h}$ group, determined by one-way analysis of variance. AST-IV, astragaloside IV; DMSO, dimethyl sulfoxide.

(Invitrogen; Thermo Fisher Scientific, Inc.). The RNA integrity was analyzed on a $1.0 \%$ agarose gel and detection of RNA quantity was performed using a NanoDrop 2000C Spectrophotometer (Thermo Fisher Scientific, Inc.). Subsequently, $1 \mu \mathrm{g}$ of total RNA was reverse transcribed with a PrimeScript ${ }^{\mathrm{TM}}$ RT reagent kit (Takara Biotechnology Co., Ltd., Dalian, China) for cDNA synthesis and genomic DNA removal, according to the manufacturer's protocol. The qPCR procedure was performed on the basis of the instructions of the SYBR premix Ex Taq ${ }^{\mathrm{TM}}$ II kit (Tli RNaseH Plus; Takara Biotechnology Co., Ltd.) and performed in triplicate using a Takara real-time PCR system (Takara Biotechnology Co., Ltd.). The thermocycling conditions were as follows: $30 \mathrm{sec}$ at $95^{\circ} \mathrm{C}$, followed by 40 cycles at $95^{\circ} \mathrm{C}$ for $5 \mathrm{sec}$ and $60^{\circ} \mathrm{C}$ for $30 \mathrm{sec}$. Gene-specific primers were designed using the online primer design tool Primer-BLAST (http://www.ncbi.nlm. nih.gov/tools/primer-blast/). The lengths of amplifications were between 100 and 250 bp. GAPDH served as an internal control. The specificity of amplification was evaluated by the analysis of the dissociation curve, and the relative abundance of genes was determined using the $2^{-\Delta \Delta C q}$ method (29). The primer sequences were as follows: SHH forward, 5'-GTGGCC GAGAAGACCCTA-3' and reverse, 5'-CAAAGCGTTCAA CTTGTCCTTA-3'; GLI1 forward, 5'-CGGGCACCATCC ATTTCTAC-3' and reverse, 5'-GGCACAGTCAGTCTGCTT TCCT-3'; and GAPDH forward, 5'-GCACCGTCAAGGCTG AGAAC-3' and reverse, 5'-TGGTGAAGACGCCAGTGGA-3'.

Western blot analysis. Total protein was isolated with RIPA lysis buffer (Pulilai Gene Technology Co., Ltd., Beijing, China). The cells were lysed in RIPA buffer on ice for $30 \mathrm{~min}$, and supernatant was then collected through centrifugation at $12,000 \mathrm{x} \mathrm{g}$ for $5 \mathrm{~min}$ at $4^{\circ} \mathrm{C}$. Protein concentrations were determined with a BCA protein assay kit (Pulilai Gene Technology Co., Ltd.). Total proteins ( $40 \mu \mathrm{g}$ protein/lane) were separated by $12 \%$ SDS-PAGE and transferred onto a PVDF membrane. The membrane was blocked with $5 \%(\mathrm{~W} / \mathrm{V})$ non-fat milk at room temperature for $1 \mathrm{~h}$, incubated with primary antibodies against Shh (1:1,000; cat. no. 2207), Gli1 (1:1,000; cat. no. 3538) and $\beta$-actin (1:1,000; cat. no. 4970$)$ at $4^{\circ} \mathrm{C}$ overnight, and then incubated with anti-rabbit $\operatorname{IgG}$ horseradish peroxidase-conjugated secondary antibody (1:2,000; cat. no. 7074) (all from Cell 
Signaling Technology, Inc., Danvers, MA, USA) at room temperature for $1 \mathrm{~h}$. The bands were visualized with an ECL reagent (Thermo Fisher Scientific, Inc.). $\beta$-actin was used as the loading control.

Statistical analysis. All results are expressed as the mean \pm standard deviation of three independent experiments performed in triplicate. Statistical analyses were performed using the SPSS 17.0 software package (SPSS, Inc., Chicago, IL, USA) and one-way analysis of variance with Dunnett's test was used to compare the means between two groups. $\mathrm{P}<0.05$ was considered to indicate a statistically significant difference.

\section{Results}

Astragaloside IV promotes the proliferation of human osteoblast-like cells. To investigate the effects of astragaloside IV on osteogenesis in human osteoblast-like cells, cell growth and proliferation were analyzed. The structure of astragaloside IV was drawn using Chemdraw 14.0 (Fig. 1A). A CCK-8 assay was performed to detect cell growth. The MG-63 and $\mathrm{U}-2 \mathrm{OS}$ cells were treated with increasing concentrations of astragaloside IV $\left(1 \times 10^{-5}, 1 \times 10^{-4}, 1 \times 10^{-3}, 1 \times 10^{-2}, 1 \times 10^{-1}, 1\right.$, and $10 \mu \mathrm{g} / \mathrm{ml}$ ) for $48 \mathrm{~h}$. The results showed that astragaloside IV at the indicated concentrations (MG-63, $1 \times 10^{-2} \mu \mathrm{g} / \mathrm{ml}$; $\left.\mathrm{U}-2 \mathrm{OS}, 1 \times 10^{-3} \mu \mathrm{g} / \mathrm{ml}\right)$ significantly increased the growth of the human osteoblast-like cells $(\mathrm{P}<0.05$, Fig. 1B and $\mathrm{C})$. As a further demonstration of the association between time and the concentration of astragaloside IV following 24, 48, 72 and $96 \mathrm{~h}$ of treatment, the MG-63 and U-2OS cells treated with astragaloside IV for $48 \mathrm{~h}$ (MG-63, $1 \times 10^{-2} \mu \mathrm{g} / \mathrm{ml}$; U-2OS, $1 \times 10^{-3} \mu \mathrm{g} / \mathrm{ml}$ ) had significantly decreased cell proliferation rate was observed $(\mathrm{P}<0.05$, Fig. $1 \mathrm{D}$ and $\mathrm{E})$. Taken together, the results indicated that astragaloside IV increased the growth and proliferation of the human osteoblast-like cells.

Astragaloside IV stimulates the migration of human osteoblast-like cells. The migratory capacity of osteoblasts is key in osteogenesis. To evaluate the functions of astragaloside IV in MG-63 and U-2OS cell migration efficiency, a wound-healing assay and Transwell cell migration assay were performed. Astragaloside IV was observed to markedly induce the wound-healing of MG-63 and U-2OS cells following pre-treatment for $48 \mathrm{~h}(\mathrm{P}<0.05$, Fig. $2 \mathrm{~A}$ and B). Furthermore, the results of the Transwell cell migration analysis demonstrated that the cell migration efficiencies of the MG-63 and U-2OS cells were enhanced following astragaloside IV treatment for 24 or $48 \mathrm{~h}$, and the differences were significant when compared with the control group $(\mathrm{P}<0.05$, Fig. $2 \mathrm{C}$ and $\mathrm{D})$. These results indicated that astragaloside IV is critical for stimulating the migration of human osteoblast-like cells.

Astragaloside IV enhances the hedgehog signaling pathway. Several studies have suggested that the Shh-induced hedgehog pathway is crucial for regulating the proliferation and migration of tumor cells and promoting the proliferation, differentiation and maturation of osteoblasts. The present study investigated whether astragaloside IV affects the hedgehog signaling pathway. To investigate the role of the hedgehog signaling pathway in astragaloside IV-enhanced cell proliferation and migration, the human osteoblast-like cells were treated with cyclopamine, which is an inhibitor of Smo, to inhibit the hedgehog pathway (30). The MG-63 and U-2OS cells were treated with increasing concentrations of cyclopamine $(2.5,5.0,7.5$, and $10 \mu \mathrm{mol} / \mathrm{l})$ for $48 \mathrm{~h}$. The cell viability analysis using the CCK-8 assay demonstrated that cyclopamine significantly suppressed the growth of the MG-63 and U-2OS cells in a dose-dependent manner (Fig. 3A and B).

Ptch1 and Ptch2 are 12-pass transmembrane proteins that function as Hh receptors. When the hedgehog signal Shh binds to Ptch (Ptch1 and Ptch2), suppressor of fused (Sufu), as a suppressor of fused kinase, positively regulates hedgehog signaling and the active nuclear transcription factor Gli1 (Fig. 3C).

The present study aimed to detect the mechanism of action of astragaloside IV combined with cyclopamine on components of the hedgehog signaling pathway. The results of the RT-qPCR and western blot analyses results demonstrated that the mRNA and protein levels of SHH and GLI1 were significantly upregulated in MG-63 and U-2OS cells treated with astragaloside IV for $48 \mathrm{~h}$ (Fig. 3D and E). The mRNA and protein expression levels of GLI1 and SHH were marginally elevated in cells treated with astragaloside IV combined with cyclopamine, however the increase was markedly reduced, compared with that in MG-63 and U-2OS cells treated with astragaloside IV (Fig. 3F and G).

The results of the analysis of gene expression levels of $\mathrm{SHH}$ and GLII in MG-63 and U-2OS cells following treatment with astragaloside IV suggested that astragaloside IV promoted activation of the hedgehog signaling pathway.

Hedgehog signaling pathway inhibitor eliminates astragaloside IV-induced proliferation and migration of the osteoblast-like cells. The present study then analyzed the effect of astragaloside IV combined with cyclopamine on cell proliferation in human osteoblast-like cells. In the MG-63 cells, the two drugs acted together to inhibit cell proliferation, and the percentage of cells in the S phase was reduced. In the U-2OS cells, there was no effect on cell proliferation compared with the control (Fig. 4A and B). These results indicated that the effect of astragaloside IV on osteoblast-like cell proliferation was reduced by cyclopamine.

Furthermore, the Transwell cell migration assay was used to assess the impact of cyclopamine on cell migration efficiency. The results demonstrated that the cell migration ability of MG-63 and U-2OS cells was promoted following treatment with astragaloside IV combined with cyclopamine for $48 \mathrm{~h}$ $(\mathrm{P}<0.05$, Fig. $4 \mathrm{C}$ and $\mathrm{D})$; however, the cell migration efficiency was lower than that resulting from the treatment of osteoblast-like cells with astragaloside IV alone. Taken together, these findings suggested that astragaloside IV-promoted cell proliferation and migration, and that these effects were significantly inhibited by hedgehog signaling pathway inhibition.

\section{Discussion}

In the process of bone remodeling, bone is continuously broken down and reformed, which occurs through the balance between osteoblasts and osteoclasts (31). Osseointegration comprises a cascade of complex mechanisms. First, the drilling 

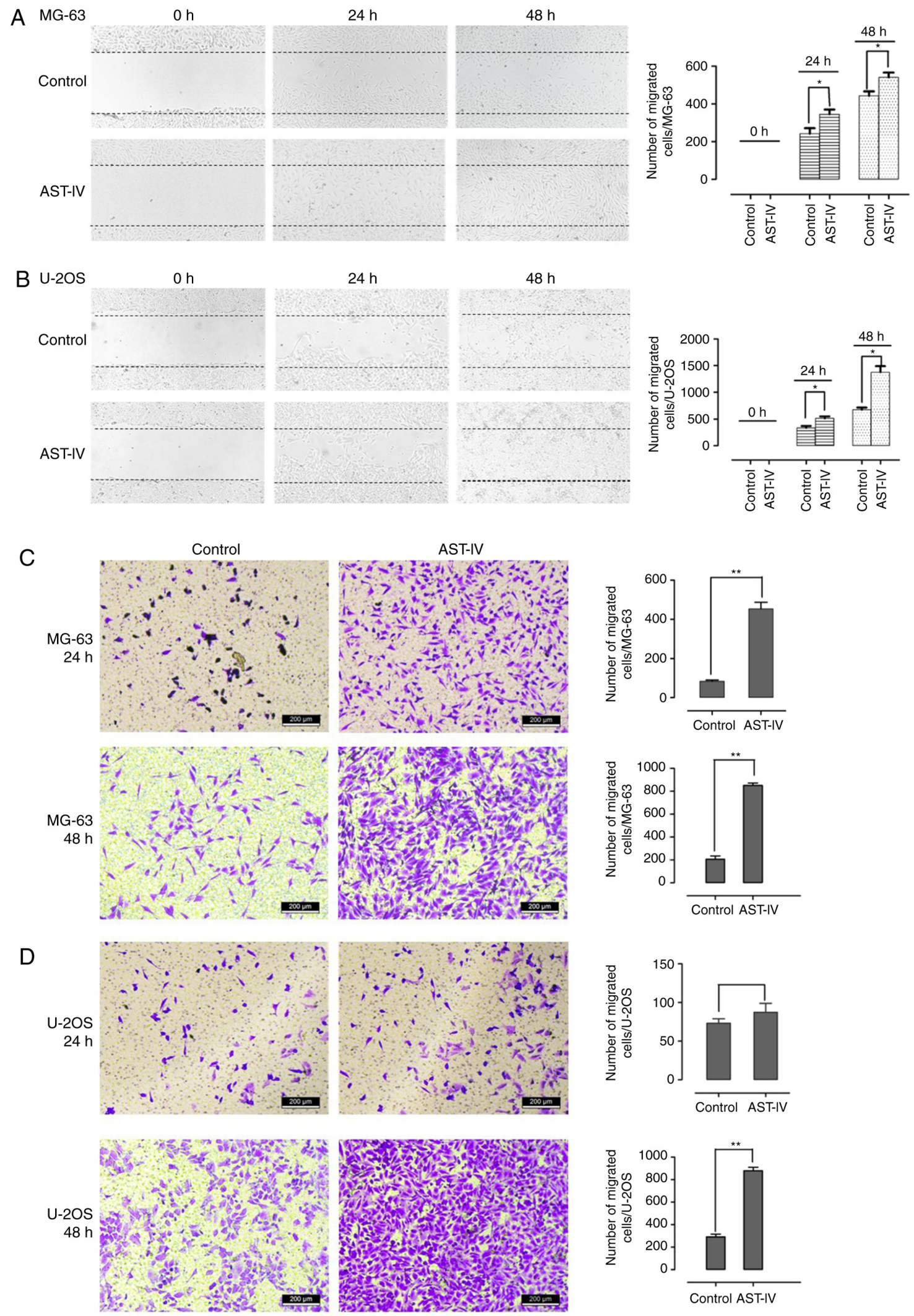

Figure 2. AST-IV increases the migration of MG-63 and U-2OS cells in vitro. When the cells had been treated with dimethyl sulfoxide as a control or AST-IV (MG-63, 1x10-2 $\mu \mathrm{g} / \mathrm{ml}$; U-2OS, $1 \times 10^{-3} \mu \mathrm{g} / \mathrm{ml}$ ) for $48 \mathrm{~h}$, a wound-healing assay for the (A) MG-63 and (B) U-2OS cells, and a Transwell cell migration assay for the (C) MG-63 and (D) U-2OS cells, were performed to evaluate the effects of AST-IV on the metastasis of the cell lines, shown by representative images. The number of migrated cells per high-power field was determined, as shown in the graphs. Data are presented as the mean + standard deviation $(n=3),{ }^{*} \mathrm{P}<0.05$ and ${ }^{* *} \mathrm{P}<0.01$, determined by one-way analysis of variance. AST-IV, astragaloside IV.

of an implant cavity is a traumatic insult to bone and leads to distinct phases of wound healing $(32,33)$. Secondly, new bone is generated from the borders of the drill hole (distance osteogenesis) or from osteogenic cells on the surface of the 

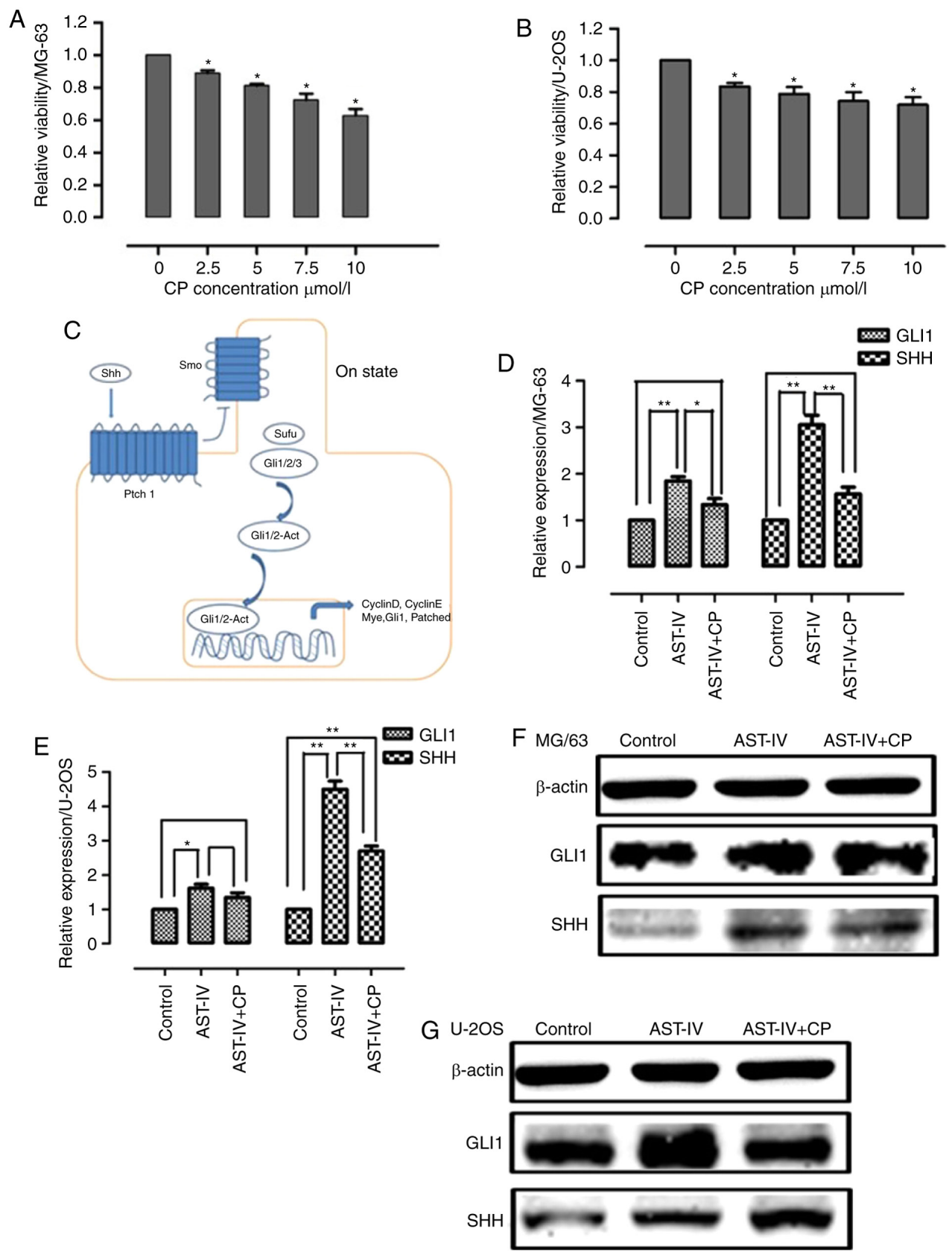

Figure 3. AST-IV regulates the mRNA and protein levels of hedgehog signaling pathway components in MG-63 and U-2OS cells. (A) MG-63 and (B) U-2OS cells were treated with CP $(2.5,5.0,7.5$, and $10.0 \mu \mathrm{g} / \mathrm{ml})$ for $48 \mathrm{~h}$, and cell growth was assessed using a Cell Counting Kit- 8 array. Data are presented as the mean + standard deviation of three independent experiments. (C) Components detected in the hedgehog signaling pathway. Expression levels of GLII and $S H H$ genes were detected in MG-63 and U-2OS cells following treatment with dimethyl sulfoxide as a control or AST-IV (MG-63, $1 \times 10^{-2} \mu \mathrm{g} / \mathrm{ml}$; U-2OS, $1 \times 10^{-3} \mu \mathrm{g} / \mathrm{ml}$ ) or AST-IV (MG-63, $1 \times 10^{-2} \mu \mathrm{g} / \mathrm{ml}$; U-2OS. $\left.1 \times 10^{-3} \mu \mathrm{g} / \mathrm{ml}\right)$ combined with CP $(2.5 \mu \mathrm{mol} / 1)$ for 48 h. mRNA levels in the (D) MG-63 and (E) U-2OS cells were analyzed by reverse transcription-quantitative polymerase chain reaction analysis and normalized to GAPDH. Protein expression levels in (F) MG-63 and (G) U-2OS were analyzed by western blot analysis. Actin was used as an internal control. ${ }^{*} \mathrm{P}<0.05$ and ${ }^{* *} \mathrm{P}<0.01$. Experiments were performed in triplicate, determined by one-way analysis of variance. AST-IV, astragaloside IV; CP, cyclopamine; GLI1, GLI family zinc finger 1; SHH, sonic hedgehog.

implant (contact osteogenesis). In distance osteogenesis, osteoblasts migrate to the surface of the implant cavity, whereas in contact osteogenesis, osteogenic cells migrate directly onto the implant surface and generate new bone (34). Therefore, the proliferative ability and migratory behavior of osteoblasts are key in osseointegration (35).

The optimization of the implant surface assists in promoting osseointegration by promoting the migration, adhesion, proliferation and differentiation of osteoblasts.
Sandblasting, etching, and hydrophilicity have been successfully used on the implant surface. To further improve the speed and quality of osseointegration, novel methods of surface modification, including discrete crystal deposition, laser ablation, surface coating and surface treatment with proteins, drugs or growth factors, are being investigated (36). The present study demonstrated that astragaloside IV can promote the proliferation and migration of human osteoblast-like cells. 

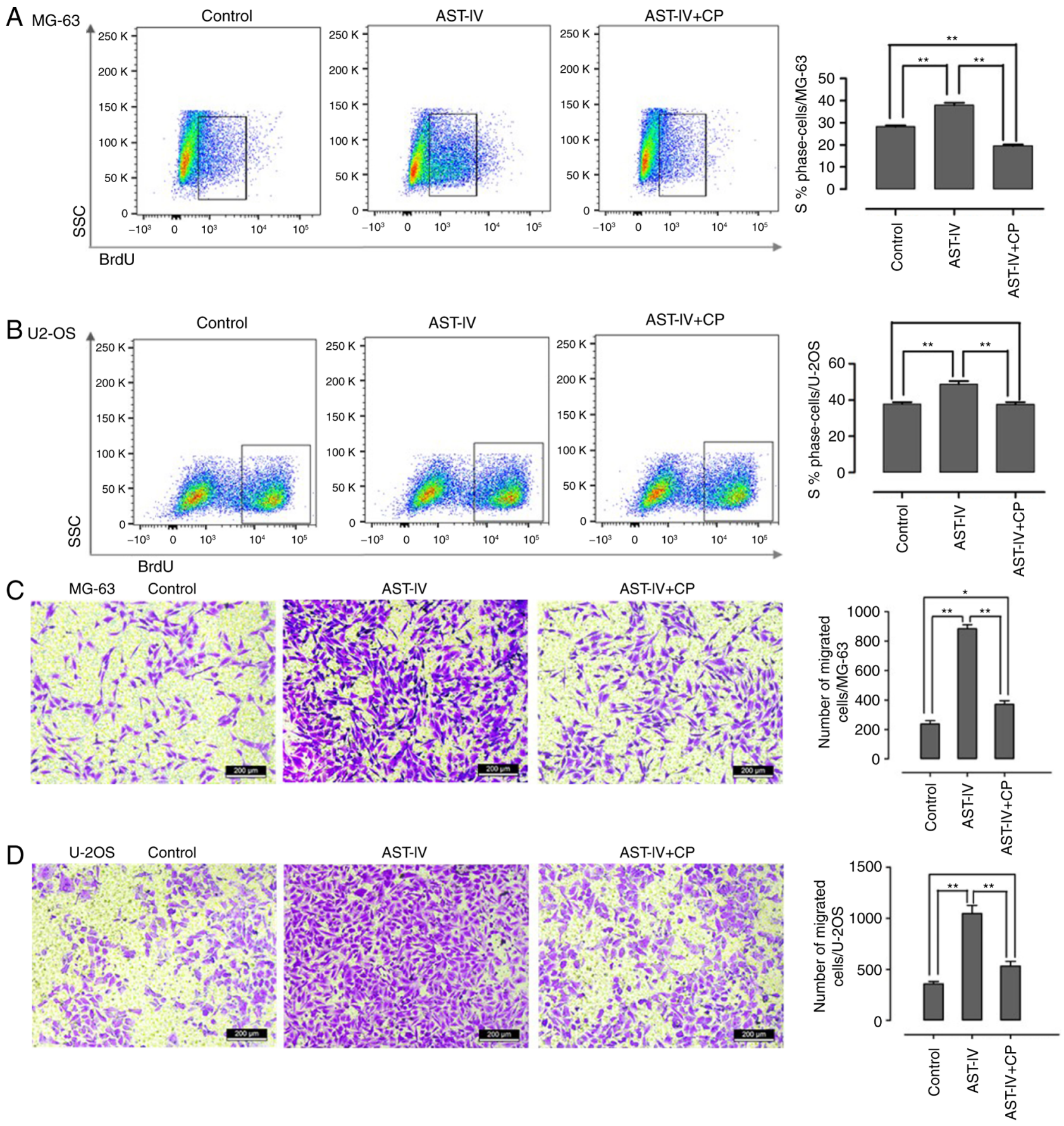

Figure 4. CP decreases the cell proliferation and migration promoted by AST IV in MG-63 and U-2OS cells. Following treatment of human osteoblast-like cells with AST-IV (MG-63, 1x10-2 $\mu \mathrm{g} / \mathrm{ml}$; U-2OS, $\left.1 \times 10^{-3} \mu \mathrm{g} / \mathrm{ml}\right)$ combined with CP $(2.5 \mu \mathrm{mol} / \mathrm{l})$ or dimethyl sulfoxide as a control for $48 \mathrm{~h}$, BrdU was added for $4 \mathrm{~h}$, and flow cytometry was used to analyze (A) MG-63 and (B) U-2OS cell proliferation. Data are presented as the mean + standard deviation (n=3). Transwell cell migration assays were performed to detect the migration of (C) MG-63 and (D) U-2OS cells, shown by representative images and quantification of migrated cells per high power field in the graphs. Data are presented as the mean + standard deviation $(\mathrm{n}=3)$. ${ }^{\mathrm{P}} \mathrm{P}<0.05$ and ${ }^{* * *} \mathrm{P}<0.01$, determined by one-way analysis of variance. AST-IV, astragaloside IV; CP, cyclopamine.

The effects of various doses of astragaloside IV $\left(1 \times 10^{-5}-10 \mu \mathrm{g} / \mathrm{ml}\right)$ for $48 \mathrm{~h}$ on human osteosarcoma cells in vitro were examined in the present study. The results indicated that astragaloside IV promoted MG-63 cell and U-2OS cell proliferation and migration, respectively, at relatively low concentrations (MG-63 cells, $1 \times 10^{-2} \mu \mathrm{g} / \mathrm{ml}$; U-2OS cells, $1 \times 10^{-3} \mu \mathrm{g} / \mathrm{ml}$ ). Several previous studies have reported that a high concentration of astragaloside IV $(10-100 \mu \mathrm{g} / \mathrm{ml})$ can inhibit tumor cell growth, migration and invasion in lung cancer (37), breast cancer (8), hepatoma (38), and glioma (39). In addition, the content of astragaloside IV in Astragali Radix is $\sim 0.04 \%$, and the clinical application dosage of Astragali Radix is $\sim 20 \mathrm{~g}$ per day. Therefore, there is $\sim 8 \mu \mathrm{g}$ of astragaloside IV in $20 \mathrm{~g}$ of Astragali Radix. The results of the in vitro experiments in the present study indicated that astragaloside IV promoted MG-63 cell and U-2OS cell proliferation and migration, respectively, at relatively low concentrations (MG-63 cells, $1 \times 10^{-2} \mu \mathrm{g} / \mathrm{ml}$; $\mathrm{U}-2 \mathrm{OS}$ cells, $1 \times 10^{-3} \mu \mathrm{g} / \mathrm{ml}$ ). This result indicated that the 
dosage of astragaloside IV required in promoting the proliferation and migration of osteoblast-like cells is lower than the clinical application dosage of Astragali Radix.

Previous studies have reported that numerous cytokines are involved in the proliferation and migration of bone cells, including bone morphogenetic protein, insulin like growth factor, and wingless and int ligands. Furthermore, they have demonstrated that high mobility group box 1 protein (HMGB1) significantly promotes the migration of osteoblasts in vitro and the Toll-like receptor (TLR)2/TLR4-dependent nuclear factor- $\kappa \mathrm{B}$ pathway is involved in HMGB1-induced osteoblast migration (40-43). In the present study the hedgehog signaling pathway was found to be involved in the process of astragaloside IV-enhanced cell proliferation and migration in MG-63 and U-2OS cells.

Shh is a $45-\mathrm{kDa}$ signal protein that regulates the proliferation, differentiation and morphology of numerous cell types. Several studies have reported that the hedgehog signaling pathway is important in the proliferation and differentiation of osteoblasts, and is involved in fracture healing and bone repair $(44,45)$. Gli1 and Gli2 proteins are the main transcription factors in hedgehog signaling. Shh can activate Gli1 and Gli2, and high protein expression levels of Gli1 and Gli2 indicate that the hedgehog signaling pathway is activated. The activation of Gli1 and Gli2 can directly promote the expression of a set of genes, including oncogenes and genes involved in cell cycle, for example, Cyclin D, Cyclin E and Myc.

In the present study, the expression of key proteins in the hedgehog signaling pathway in human osteoblast-like cells were detected following treatment with astragaloside IV. The results demonstrated that astragaloside IV caused a marked increase in the mRNA and protein levels of GLI1 and SHH, culminating in the observation that astragaloside IV activated hedgehog signaling.

To further investigate whether astragaloside IV potentiated the osteogenesis of human osteoblast cells via the hedgehog signaling pathway, the cells were treated with cyclopamine. Cyclopamine is an inhibitor of the hedgehog signaling pathway, is naturally produced and belongs to the group of steroidal jerveratrum alkaloids. The results indicated that the effect of astragaloside IV on cell proliferation and migration was markedly reduced by cyclopamine. Following treatment with astragaloside IV combined with cyclopamine in MG-63 and $\mathrm{U}-2 \mathrm{OS}$ cells, the increase in the expression of genes involved in hedgehog signaling was not statistically significant.

In conclusion, the findings of the present study suggested that activation of the hedgehog signaling pathway by astragaloside IV significantly enhanced human osteoblast-like cell proliferation and migration, and that astragaloside IV may serve as a growth factor to promote osseointegration. To the best of our knowledge, the present study is the first to demonstrate the effect of astragaloside IV on osteoblasts and that the hedgehog signaling pathway was the direct target of astragaloside IV. These results identify a therapeutic target for the promotion of bone formation in implants and a rationale for the development of astragaloside IV for use in clinical therapy.

\section{Acknowledgements}

Not applicable.

\section{Funding}

The present study was supported by the National Natural Science Foundation of China (grant no. 81371115) and the Fundamental Research Funds for the Central Public Welfare research Institutes (grant no. ZZ11-071).

\section{Availability of data and materials}

All data generated or analyzed during this study are included in this published article.

\section{Authors' contributions}

JL and YH designed the study. JL and YC produced the outline and reviewed the manuscript. YC and LHG analyzed all the results. LHG performed the majority of the experiments and drafted the manuscript. RTZ performed the statistical analysis and figure editing. All authors read and approved the final manuscript.

\section{Ethics approval and consent to participate}

Not applicable.

\section{Patient consent for publication}

Not applicable.

\section{Competing interests}

The authors declare that they have no competing interests.

\section{References}

1. Li JY, Zheng LW, Ma L, Kwong DL, Cheung LK and Pow EH: Effect of fluoride-modified titanium surface on early adhesion of irradiated osteoblasts. Biomed Res Int: 19752, 2015.

2. Annibali S, Pranno N, Cristalli MP, La Monaca G and Polimeni A: Survival analysis of implant in patients with diabetes mellitus: A systematic review. Implant Dent 25: 663-674, 2016.

3. Zhang ND, Han T, Huang BK, Rahman K, Jiang YP, Xu HT, Qin LP, Xin HL, Zhang QY and Li YM: Traditional Chinese medicine formulas for the treatment of osteoporosis: Implication for antiosteoporotic drug discovery. J Ethnopharmacol 189: 61-80, 2016

4. Zhang WD, Zhang C, Liu RH, Li HL, Zhang JT, Mao C, Moran S and Chen CL: Preclinical pharmacokinetics and tissue distribution of a natural cardioprotective agent astragaloside IV in rats and dogs. Life Sci 79: 808-815, 2006.

5. Luo Y, Qin Z, Hong Z, Zhang X, Ding D, Fu JH, Zhang WD and Chen J: Astragaloside IV protects against ischemic brain injury in a murine model of transient focal ischemia. Neurosci Lett 363: 218-223, 2004

6. Zhang WJ, Hufnagl P, Binder BR and Wojta J: Antiinflammatory activity of astragaloside IV is mediated by inhibition of NF-kappaB activation and adhesion molecule expression. Thromb Haemost 90: 904-914, 2003.

7. Zhang S, Tang D, Zang W, Yin G, Dai J, Sun YU, Yang Z, Hoffman RM and Guo X: Synergistic inhibitory effect of traditional Chinese medicine astragaloside IV and curcumin on tumor growth and angiogenesis in an orthotopic nudemouse model of human hepatocellular carcinoma. Anticancer Res 37: 465-473, 2017.

8. Jiang K, Lu Q, Li Q, Ji Y, Chen W and Xue X: Astragaloside IV inhibits breast cancer cell invasion by suppressing Vav3 mediated Rac1/MAPK signaling. Int Immunopharmacol 42: 195-202, 2017. 
9. Xia B, Xu B, Sun Y, Xiao L, Pan J, Jin H and Tong P: The effects of Liuwei Dihuang on canonical Wnt $/ \beta$-catenin signaling pathway in osteoporosis. J Ethnopharmacol 153: 133-141, 2014.

10. Kang SC, Kim HJ and Kim MH: Effects of Astragalus membranaceus with supplemental calcium on bone mineral density and bone metabolism in calcium-deficient ovariectomized rats. Biol Trace Elem Res 151: 68-74, 2013.

11. Zhang ZG, Wu L, Wang JL, Yang JD, Zhang J, Zhang J, Li LH, Xia Y, Yao LB, Qin HZ and Gao GD: Astragaloside IV prevents MPP+-induced SH-SY5Y cell death via the inhibition of Bax-mediated pathways and ROS production. Mol Cell Biochem 364: 209-216, 2012.

12. Li M, Yu L, She T, Gan Y, Liu F, Hu Z, Chen Y, Li S and Xia H: Astragaloside IV attenuates Toll-like receptor 4 expression via $\mathrm{NF}-\kappa \mathrm{B}$ pathway under high glucose condition in mesenchymal stem cells. Eur J Pharmacol 696: 203-209, 2012.

13. Haiyan H, Rensong Y, Guoqin J, Xueli Z, Huaying $X$ and Yanwu X: Effect of Astragaloside IV on neural stem cell transplantation in Alzheimer's disease rat models. Evid Based Complement Alternat Med 2016: 3106980, 2016

14. Wang S, Chen J, Fu Y and Chen X: Promotion of Astragaloside IV for EA-hy926 cell proliferation and angiogenic activity via ERK1/2 pathway. J Nanosci Nanotechnol 15: 4239-4244, 2015.

15. Xie J, Wang H, Song T, Wang Z, Li F, Ma J, Chen J, Nan Y, $\mathrm{Yi} \mathrm{H}$ and Wang W: Tanshinone IIA and astragaloside IV promote the migration of mesenchymal stem cells by up-regulation of CXCR4. Protoplasma 250: 521-530, 2013.

16. Li M, Wang W, Geng L, Qin Y, Dong W, Zhang X, Qin A and Zhang M: Inhibition of RANKL-induced osteoclastogenesis through the suppression of the ERK signaling pathway by astragaloside IV and attenuation of titanium-particle-induced osteolysis. Int J Mol Med 36: 1335-1344, 2015.

17. Alman BA: The role of hedgehog signaling in skeletal health and disease. Nat Rev Rheumatol 11: 552-560, 2015.

18. Jemtland R, Divieti P, Lee K and Segre GV: Hedgehog promotes primary osteoblast differentiation and increases PTHrP mRNA expression and iPTHrP secretion. Bone 32: 611-620, 2003.

19. Yang J, Andre P, Ye L and Yang YZ: The Hedgehog signalling pathway in bone formation. Int J Oral Sci 7: 73-79, 2015.

20. Nakamura T, Aikawa T, Iwamoto-Enomoto $M$, Iwamoto $M$, Higuchi Y, Pacifici M, Kinto N, Yamaguchi A, Noji S, Kurisu $\mathrm{K}$, et al: Induction of osteogenic differentiation by hedgehog proteins. Biochem Biophys Res Commun 237: 465-469, 1997.

21. Enomoto-Iwamoto M, Nakamura T, Aikawa T, Higuchi Y, Yuasa T, Yamaguchi A, Nohno T, Noji S, Matsuya T, Kurisu K, et al: Hedgehog proteins stimulate chondrogenic cell differentiation and cartilage formation. J Bone Miner Res 15 : 1659-1668, 2000.

22. Ingham PW and McMahon AP: Hedgehog signaling in animal development: Paradigms and principles. Genes Dev 15: 3059-3087, 2001

23. Mas C and Ruiz i Altaba A: Small molecule modulation of HH-GLI signaling: Current leads, trials and tribulations. Biochem Pharmacol 80: 712-723, 2010.

24. Thayer SP, di Magliano MP, Heiser PW, Nielsen CM, Roberts DJ, Lauwers GY, Qi YP, Gysin S, Fernández-del Castillo C, Yajnik $\mathrm{V}$, et al: Hedgehog is an early and late mediator of pancreatic cancer tumorigenesis. Nature 425: 851-856, 2003

25. Fukaya M, Isohata N, Ohta H, Aoyagi K, Ochiya T, Saeki N, Yanagihara K, Nakanishi Y, Taniguchi H, Sakamoto H, et al: Hedgehog signal activation in gastric pit cell and in diffuse-type gastric cancer. Gastroenterology 131: 14-29, 2006.

26. Olive KP, Jacobetz MA, Davidson CJ, Gopinathan A, McIntyre D, Honess D, Madhu B, Goldgraben MA, Caldwell ME, Allard D, et al: Inhibition of Hedgehog signaling enhances delivery of chemotherapy in a mouse model of pancreatic cancer. Science 324: 1457-1461, 2009.

27. Bar EE, Chaudhry A, Lin A, Fan X, Schreck K, Matsui W, Piccirillo S, Vescovi AL, DiMeco F, Olivi A, et al: Cyclopamine mediated Hedgehog pathway inhibition depletes stem-like cancer cells in glioblastoma. Stem Cells 25: 2524-2533, 2007.
28. Briscoe $\mathrm{J}$ and Thérond PP: The mechanisms of Hedgehog signalling and its roles in development and disease. Nat Rev Mol Cell Biol 14: 416-429, 2013.

29. Livak KJ and Schmittgen TD: Analysis of relative gene expression data using real-time quantitative PCR and the 2(-Delta Delta C(T)) method. Methods 25: 402-408, 2001.

30. Chen JK, Taipale J, Young KE, Maiti T and Beachy PA: Small molecule modulation of Smoothened activity. Proc Natl Acad Sci USA 99: 14071-14076, 2002.

31. Karsenty G: The complexities of skeletal biology. Nature 423 : 316-318, 2003

32. Von Wilmowsky C, Moest T, Nkenke E, Stelzle F and Schlegel KA: Implants in bone: Part I. A current overview about tissue response, surface modification sand future perspectives. Oral Maxillofac Surg 18: 243-257, 2014

33. Terheyden H, Lang NP, Bierbaum S and Stadlinger B: Osseointegration-communication of cells. Clin Oral Implants Res 23: 1127-1135, 2012

34. Zhou R, Wei D, Cao J, Feng W, Cheng S, Du Q, Li B, Wang Y, Jia D and Zhou Y: Synergistic effects of surface chemistry and topologic structure from modified microarc oxidation coatings on Ti implants for improving osseointegration. ACS Appl Mater Interfaces 7: 8932-8941, 2015.

35. Andrukhov O, Huber R, Shi B, Berner S, Rausch-Fan X, Moritz A, Spencer ND and Schedle A: Proliferation, behavior, and differentiation of osteoblasts on surfaces of different microroughness. Dent Mater 32: 1374-1384, 2016.

36. Smeets R, Stadlinger B, Schwarz F, Beck-Broichsitter B, Jung O, Precht C, Kloss F, Gröbe A, Heiland M and Ebker T: Impact of dental implant surface modifications on osseointegration. Biomed Res Int 2016: 6285620, 2016.

37. Cheng X, Gu J, Zhang M, Yuan J, Zhao B, Jiang J and Jia X: Astragaloside IV inhibits migration and invasion in human lung cancer A549 cells via regulating PKC- $\alpha$-ERK1/2-NF- $\kappa \mathrm{B}$ pathway. Int Immunopharmacol 23: 304-313, 2014.

38. Qin CD, Ma DN, Ren ZG, Zhu XD, Wang CH, Wang YC, Ye BG, Cao MQ, Gao DM and Tang ZY: Astragaloside IV inhibits metastasis in hepatoma cells through the suppression of epithelial-mesenchymal transition via the Akt/GSK-3 $\beta / \beta$-catenin pathway. Oncol Rep 37: 1725-1735, 2017.

39. Li B, Wang F, Liu N, Shen W and Huang T: Astragaloside IV inhibits progression of glioma via blocking MAPK/ERK signaling pathway. Biochem Biophys Res Commun 491: 98-103, 2017.

40. Sims NA and Gooi JH: Bone remodeling: Multiple cellular interactions required for coupling of bone formation and resorption. Semin Cell Dev Biol 19: 444-451, 2008.

41. Javed A, Bae JS, Afzal F, Gutierrez S, Pratap J, Zaidi SK, Lou Y, van Wijnen AJ, Stein JL, Stein GS and Lian JB: Structural coupling of Smad and Runx2 for execution of the BMP2 osteogenic signal. J Biol Chem 283: 8412-8422, 2008

42. Baron R and Kneissel M: WNT signaling in bone homeostasis and disease: From human mutations to treatments. Nat Med 19: 179-192, 2013.

43. Li MJ, Li F, Xu J, Liu YD, Hu T and Chen JT: rhHMGB1 drives osteoblast migration in a TLR2/TLR4- and NF- $\mathrm{BB}$-dependent manner. Biosci Rep 36: e00300, 2016.

44. Horikiri Y, Shimo T, Kurio N, Okui T, Matsumoto K, Iwamoto M and Sasaki A: Sonic hedgehog regulates osteoblast function by focal adhesion kinase signaling in the process of fracture healing. PLoS One 8: e76785, 2013.

45. Kimura $\mathrm{H}, \mathrm{Ng} \mathrm{JM}$ and Curran T: Transient inhibition of the Hedgehog pathway in young mice causes permanent defects in bone structure. Cancer Cell 13: 249-260, 2008.

This work is licensed under a Creative Commons Attribution-NonCommercial-NoDerivatives 4.0 International (CC BY-NC-ND 4.0) License. 